\title{
ASSESSMENTS CONCERNING THE DURABILITY OF THICK-WALLED PIPES OBTAINED BY SHRINKAGE
}

\author{
PINTILIE, G[heorghe] \& ALBUT, A[urelian]
}

\begin{abstract}
This paper presents a comparison analysis between the durability of thick walled pipes obtained with and without shrinkage. On the fist part of the article is presented the theoretical aspects regarding the stress state from the thickwalled pipes considering three individual cases: regular pipe loaded with internal pressure; pipe obtained by shrinkage, loaded by shrinkage pressure; shrink pipe loaded by shrinkage and internal pressure. On the second part it is shown the numerical analysis concerning the pipe durability, for both cases with and without shrinkage, highlighting the influence of some constructive parameters as thickness of the pipe wall and the shrinkage pressure. The numerical analysis has been done using the NASGRO 5.01 software [1].

Keywords: crack propagation, durability, shrinkage, life prediction
\end{abstract}

\section{INTRODUCTION}

This In the industrial applications are used thickwalled pipes loaded with very high internal pressure, hundreds of . Due to this high pressure, to increase the pipe resistance, different technological solutions are used. Good results are obtained by using pipes obtained by shrinkage. Shrinkage is a process in which two pipes are assembled together by heating the outer pipe and cooling the inner pipe.

The objective of this paper is to emphasize the improvement of durability in case of the shrinkage pipe compared with an regular pipe. The presented work is focused on the influence of the shrinkage pressure on the pipe durability. Knowing the influence of this parameter on the pipe durability, it will be possible to design a pipe with longer lifetime.

\section{THE STRESS STATE IN CASE OF THICK- WALLED PIPES}

Using the notations from fig.1 the following equations can be written [2]:

- Radial stress and circumferential stress that is initiated in a random point $\mathrm{M}$ from the pipe wall:

- Radial displacement of the M point is described by the following equation:

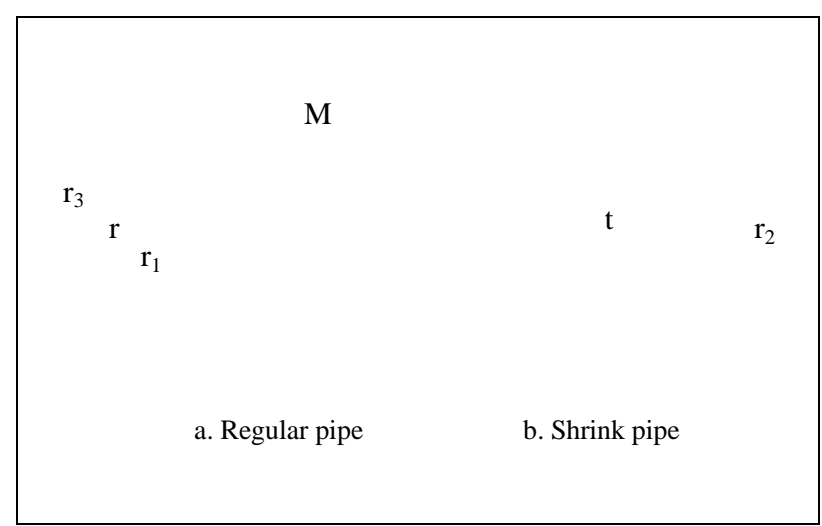

Fig. 1. Geometrical characteristics of the thick-walled pipe

In the following part will be analised, separatly, the case of regular pipe loaded only with internal pressure

, the case of shrinkage pipe loaded with shrinkage pressure and the case of shrinkage pipe loaded with internal pressure

a. The stress state in case of a regular pipe loaded with internal pressure . From equations (1) and (2) is obtained [3]:

b. The stress state in case of a shrinkage pipe. Before shrinkage process, the outer radius $r_{2}$ of the inner pipe it was greater with $\delta$ comparing with the inner radius $r_{2}$ of the outer pipe. By shrinkage process those two radius are becoming equal, so is possible to add the following condition:

in which:

represents the radial displacement of a point from the outer surface of the inner pipe 
- $\quad u_{2}$ represents the radial displacement of a point from the inner surface of the outer pipe.

From condition (6) together with equation (3) it results the formula that describe the shrinking pressure, which take place between inner and outer pipe [4].

$$
p_{f}=\frac{\delta \cdot E}{2} \frac{\left(r_{2}^{2}-r_{1}^{2}\right)\left(r_{3}^{2}-r_{2}^{2}\right)}{r_{2}^{2}\left(r_{3}^{2}-r_{1}^{2}\right)}
$$

Taking into account that this pressure is generated at the inside surface of the outer pipe and at the outer surface of the inner pipe, using the equation (1) and (2), it can be written [5]:

For the inner pipe loaded with outside pressure

$$
\begin{gathered}
\sigma_{r}=-p_{f} \frac{r_{2}^{2}}{r_{2}^{2}-r_{1}^{2}} \cdot\left(1-\frac{r_{1}^{2}}{r^{2}}\right) \\
\sigma_{\theta}=-p_{f} \frac{r_{2}^{2}}{r_{2}^{2}-r_{1}^{2}} \cdot\left(1+\frac{r_{1}^{2}}{r^{2}}\right)
\end{gathered}
$$

For the outside pipe loaded with inside pressure

$$
\begin{aligned}
& \sigma_{r}=p_{f} \frac{r_{2}^{2}}{r_{3}^{2}-r_{2}^{2}} \cdot\left(1-\frac{r_{3}^{2}}{r^{2}}\right) \\
& \sigma_{\theta}=p_{f} \frac{r_{2}^{2}}{r_{3}^{2}-r_{2}^{2}} \cdot\left(1+\frac{r_{3}^{2}}{r^{2}}\right)
\end{aligned}
$$

c. The stress state in case of a shrink pipe loaded with inside pressure . In this case, the solution is determined by applying the principle of overlapping effects, using the results obtained for previous mentioned cases a and $\mathrm{b}$. The obtained equations are [6]:

$$
\begin{aligned}
& \sigma_{r}=p_{i} \frac{r_{1}^{2}}{r_{3}^{2}-r_{1}^{2}} \cdot\left(1-\frac{r_{3}^{2}}{r^{2}}\right)-p_{f} \frac{r_{2}^{2}}{r_{2}^{2}-r_{1}^{2}} \cdot\left(1-\frac{r_{1}^{2}}{r^{2}}\right) \\
& \sigma_{\theta}=p_{i} \frac{r_{1}^{2}}{r_{3}^{2}-r_{1}^{2}} \cdot\left(1+\frac{r_{3}^{2}}{r^{2}}\right)-p_{f} \frac{r_{2}^{2}}{r_{2}^{2}-r_{1}^{2}} \cdot\left(1+\frac{r_{1}^{2}}{r^{2}}\right)
\end{aligned}
$$

only for $r_{1} \leq r \leq r_{2}$;

$$
\begin{aligned}
& \sigma_{r}=p_{i} \frac{r_{1}^{2}}{r_{3}^{2}-r_{1}^{2}} \cdot\left(1-\frac{r_{3}^{2}}{r^{2}}\right)+p_{f} \frac{r_{2}^{2}}{r_{3}^{2}-r_{2}^{2}} \cdot\left(1-\frac{r_{3}^{2}}{r^{2}}\right) \\
& \sigma_{\theta}=p_{i} \frac{r_{1}^{2}}{r_{3}^{2}-r_{1}^{2}} \cdot\left(1+\frac{r_{3}^{2}}{r^{2}}\right)+p_{f} \frac{r_{2}^{2}}{r_{3}^{2}-r_{2}^{2}} \cdot\left(1+\frac{r_{3}^{2}}{r^{2}}\right)
\end{aligned}
$$

only for $r_{2} \leq r \leq r_{3}$.

\section{INITIATION AND PROPAGATION OF THE FATIGUE CRACK}

The stresses $\sigma_{r}$ and $\sigma_{\theta}$ have maximal values in a point situated on the inside surface of the pipe, which leads to a higher probability that the crack to initiate in this area [7].
Because in this area $\sigma_{\theta}>\sigma_{r}$, a important role in crack propagation will be played by the circumferential component of the stress, so that the crack will propagate on longitudinal direction (fig. 2). Obviously, the crack propagation speed is affected by the value of $\sigma_{\theta}$ stress and how this stress is distributed on the pipe thickness. In fig. 3 is presented the distribution of the $\sigma_{\theta}$ stress on the wall thickness, in case of the regular pipe (continuous line) according to equation (5), and in case of the shrink pipe (dotted line), according to equations (13) and (15).

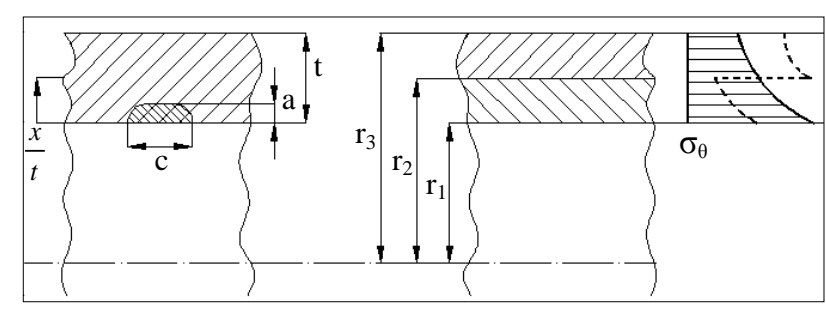

Fig. 2. Inferior crack

Fig. 3. Distribution of the $\sigma_{\theta}$ stress on the wall thickness

The curve shape corresponding to the shrink pipe depends on the inside pressure, on the shrinkage pressure and on the pipe wall thickness $t$.

\section{NUMERICAL DETERMINATION}

To determine the crack propagation speed and thus the corresponding cycles number, in the presented research is used the equation proposed by the NASGRO software:

$$
\frac{d a}{d N}=c\left[\left(\frac{1-f}{1-R}\right) \Delta K\right]^{n} \frac{\left(1-\frac{\Delta K_{t h}}{\Delta K}\right)^{p}}{\left(1-\frac{K_{\max }}{K_{c}}\right)^{q}}
$$

The signification of all the elements from equation (16) is presented in the NASGRO software documentation [1].

In this equation, the coefficients $n, p$ and $q$, are depending on the material from which the thick-walled pipe is made. For the numerical analysis, has been considered a alloy steel having the tensile strength $\sigma_{r}=723,9 \mathrm{~N} / \mathrm{mm}^{2}$, yield stress $\sigma_{c}=517,1 \mathrm{~N} / \mathrm{mm}^{2}$ and $n=2,5, p=0,25, q=0,25$.

The criterion for defining the durability has been considered the number of the loading cycles until the crack length is equal with the wall thickness (the pipe wall is penetrated).

Within the numerical determinations the following stages have been undertaken:

- Establish the stress state in the pipe wall;

- Determination of the number of cycles required for the crack to penetrate the pipe wall;

- Analysing the influence of shrinkage pressure and the influence of the thickness of the pipe wall.

\subsection{Establish the stress state in the pipe wall}

The stress state in the pipe wall have been determined for three different thickness of the pipe wall: 
- $t_{1}=60 \mathrm{~mm}\left(r_{1}=140 \mathrm{~mm} ; r_{2}=170 \mathrm{~mm} ; r_{3}=200 \mathrm{~mm}\right)$;

- $t_{2}=80 \mathrm{~mm}\left(r_{1}=120 \mathrm{~mm} ; r_{2}=155 \mathrm{~mm} ; r_{3}=200 \mathrm{~mm}\right)$;

- $t_{3}=100 \mathrm{~mm}\left(r_{1}=100 \mathrm{~mm} ; r_{2}=150 \mathrm{~mm} ; r_{3}=200 \mathrm{~mm}\right)$.

For each value of the wall thickness have been considered six values of the shrinkage pressure :22,6; 20,$41 ; 18,14 ; 15,87 ; 13,60$ and 11,34 (expressed in ). The obtained results are presented in Tab. 1,2 and 3. The $\sigma_{\theta}$ stress was calculated in 11 points, function to the $x / t$ direction (fig. 2), starting from a point situated on the inside surface of the pipe.

\begin{tabular}{|c|c|c|c|c|c|c|c|}
\hline \multirow[b]{3}{*}{$\frac{x}{t}$} & $\begin{array}{c}\text { Inner pressure } \\
p_{i}\left[\mathrm{~N} / \mathrm{mm}^{2}\right]\end{array}$ & \multicolumn{6}{|c|}{$\begin{array}{c}\text { Shrinkage pressure } \\
p_{f}\left[\mathrm{~N} / \mathrm{mm}^{2}\right]\end{array}$} \\
\hline & 100 & 22,6 & 20,41 & 18,14 & 15,87 & 13,6 & 11,34 \\
\hline & $\begin{array}{c}\text { Circumferential } \\
\text { stress } \\
\sigma_{\theta}\left[\mathrm{N} / \mathrm{mm}^{2}\right] \\
\text { Regular pipe }\end{array}$ & \multicolumn{6}{|c|}{$\begin{array}{c}\text { Circumferential stress } \sigma_{\theta}\left[\mathrm{N} / \mathrm{mm}^{2}\right] \\
\text { Shrink pipe }\end{array}$} \\
\hline 0.0 & 291,9 & 155,5 & 165,3 & 179,5 & 193,51 & 211,3 & 221,6 \\
\hline 0,1 & 276,1 & 141,6 & 154,6 & 168,2 & 181,6 & 198,7 & 208,7 \\
\hline 0,2 & 262,2 & 132,8 & 145,3 & 158,3 & 171,2 & 184,2 & 197,3 \\
\hline 0,3 & 249,8 & 124,7 & 136,9 & 149,5 & 161,9 & 174,5 & 187,0 \\
\hline 0,4 & 238,7 & 117,6 & 129,3 & 146,4 & 153,7 & 165,4 & 177,9 \\
\hline \multirow[t]{2}{*}{0,5} & \multirow[t]{2}{*}{228,8} & 111,2 & 122,7 & 134,9 & 146,2 & 158,0 & 168,8 \\
\hline & & 368,8 & 355,3 & 341,2 & 321,0 & 313,0 & 299,0 \\
\hline 0,6 & 219,9 & 354,3 & 341,4 & 337,8 & 313,9 & 300,9 & 287,2 \\
\hline 0,7 & 211,9 & 341,6 & 329,0 & 316,0 & 302,9 & 289,9 & 276,7 \\
\hline 0,8 & 204,6 & 329,8 & 317,6 & 305,0 & 292,5 & 279,9 & 267,4 \\
\hline 0,9 & 198,0 & 319,1 & 307,4 & 295,2 & 283,0 & 270,8 & 258,7 \\
\hline 1,0 & 192,0 & 309,5 & 298,1 & 286,3 & 274,5 & 262,7 & 250,9 \\
\hline
\end{tabular}

Tab. 1. Circumferential stress $\sigma_{\theta}$ for $t_{1}=60 \mathrm{~mm}$

\begin{tabular}{|c|c|c|c|c|c|c|c|}
\hline \multirow[b]{3}{*}{$\frac{x}{t}$} & $\begin{array}{c}\text { Inner pressure } \\
p_{i}\left[\mathrm{~N} / \mathrm{mm}^{2}\right]\end{array}$ & \multicolumn{6}{|c|}{$\begin{array}{l}\text { Shrinkage pressure } \\
\qquad p_{f}\left[\mathrm{~N} / \mathrm{mm}^{2}\right]\end{array}$} \\
\hline & 100 & 22,6 & 20,41 & 18,14 & 15,87 & 13,6 & 11,34 \\
\hline & $\begin{array}{c}\text { Circumferential } \\
\text { stress } \\
\sigma_{\theta}\left[\mathrm{N} / \mathrm{mm}^{2}\right] \\
\text { Regular pipe }\end{array}$ & \multicolumn{6}{|c|}{$\begin{array}{c}\text { Circumferential stress } \sigma_{\theta}\left[\mathrm{N} / \mathrm{mm}^{2}\right] \\
\text { Shrink pipe }\end{array}$} \\
\hline 0.0 & 211,0 & 98,4 & 111,0 & 122,1 & 131,9 & 143,2 & 154,5 \\
\hline 0,1 & 191,0 & 85,5 & 97,6 & 106,2 & 116,8 & 127,4 & 138,0 \\
\hline 0,2 & 177,0 & 76,8 & 86,5 & 96,7 & 106,7 & 116,8 & 127,6 \\
\hline 0,3 & 164,0 & 68,6 & 77,9 & 87,4 & 97,0 & 106,6 & 116,1 \\
\hline 0,4 & 152,0 & 60,69 & 69,5 & 78,7 & 87,8 & 97,0 & 106,1 \\
\hline \multirow[t]{2}{*}{0,5} & \multirow[t]{2}{*}{143,0} & 55,09 & 63,6 & 72,4 & 81,5 & 90,1 & 98,9 \\
\hline & & 226,6 & 221,3 & 212,5 & 203,9 & 195,2 & 186,5 \\
\hline 0,6 & 135,0 & 216,3 & 208,8 & 200,6 & 192,1 & 184,2 & 176,0 \\
\hline 0,7 & 128,0 & 205,51 & 198,0 & 190,2 & 182,4 & 174,6 & 66,8 \\
\hline 0,8 & 122,1 & 195,9 & 188,8 & 181,4 & 172,9 & 166,5 & 159,1 \\
\hline 0,9 & 116,8 & 187,5 & 180,6 & 173,5 & 166,4 & 159,3 & 152,2 \\
\hline 1,0 & 112,0 & 179,8 & 173,2 & 166,4 & 159,6 & 152,8 & 146,0 \\
\hline
\end{tabular}

Tab. 2. Circumferential stress $\sigma_{\theta}$ for $t_{2}=80 \mathrm{~mm}$

In this part of the paper, it must be emphasized the basic idea according to which the durability of a thickwalled pipe obtained by shrinkage is higher that the durability of a regular pipe. To justify this statement, the data from Tab. 2 is presented in a graphical form (fig. 4) showing the distribution of circumferential stress $\sigma_{\theta}$ on the pipe wall thickness.

It is found that for the point situated on the inside surface of the pipe (the origin from fig. 4), where is the highest probability to initiate a crack, the value of $\sigma_{\theta}$ stress for different shrinkage pressures is obviously smaller in comparison with the stress corresponding to the regular pipe. This phenomenon leads, in case of shrink pipe, to a significant delay in crack initiation and also to reduction of the crack propagation speed.

Although at $x / t=0,5$ (the contact surface between the shrinkage pipes) is recorded a pronounced leap of the $\sigma_{\theta}$ stress, the pipe durability it is not affected because the probability for crack initiation in this area is very small.

\begin{tabular}{|c|c|c|c|c|c|c|c|}
\hline \multirow[b]{3}{*}{$\frac{x}{t}$} & $\begin{array}{c}\text { Inner pressure } \\
p_{i}\left[\mathrm{~N} / \mathrm{mm}^{2}\right]\end{array}$ & \multicolumn{6}{|c|}{$\begin{array}{l}\text { Shrinkage pressure } \\
\qquad p_{f}\left[\mathrm{~N} / \mathrm{mm}^{2}\right]\end{array}$} \\
\hline & 100 & 22,6 & 20,41 & 18,14 & 15,87 & 13,6 & 11,34 \\
\hline & $\begin{array}{c}\text { Circumferential } \\
\text { stress } \\
\sigma_{\theta}\left[N / \mathrm{mm}^{2}\right] \\
\text { Regular pipe }\end{array}$ & \multicolumn{6}{|c|}{$\begin{array}{c}\text { Circumferential stress } \sigma_{\theta}\left[\mathrm{N} / \mathrm{mm}^{2}\right] \\
\text { Shrink pipe }\end{array}$} \\
\hline 0.0 & 166,5 & 84,8 & 93,0 & 103,1 & 109,3 & 117,5 & 125,6 \\
\hline 0,1 & 143,3 & 76,2 & 76,2 & 83,6 & 91,1 & 98,5 & 106,0 \\
\hline 0,2 & 125,8 & 56,1 & 63,5 & 70,4 & 77,4 & 84,3 & 91,2 \\
\hline 0,3 & 112,1 & 47,1 & 53,6 & 60,1 & 66,6 & 73,1 & 79,2 \\
\hline 0,4 & 101,1 & 35,9 & 45,7 & 51,8 & 58,0 & 64,2 & 70,3 \\
\hline \multirow[t]{2}{*}{0,5} & \multirow[t]{2}{*}{92,5} & 33,5 & 39,4 & 45,2 & 51,2 & 57,1 & 63,2 \\
\hline & & 173,0 & 164,9 & 156,9 & 148,8 & 140,8 & 132,7 \\
\hline 0,6 & 85,3 & 159,6 & 152,2 & 144,8 & 137,7 & 129,9 & 122,4 \\
\hline 0,7 & 79,3 & 148,4 & 141,1 & 134,6 & 127,7 & 120,8 & 113,8 \\
\hline 0,8 & 74,4 & 139,2 & 132,7 & 126,2 & 119,8 & 113,3 & 106,8 \\
\hline 0,9 & 70,1 & 131,1 & 125,1 & 119,0 & 112,9 & 106,8 & 100,6 \\
\hline 1,0 & 66,6 & 125,2 & 118,8 & 113,0 & 107,2 & 101,4 & 95,6 \\
\hline
\end{tabular}

Tab. 3. Circumferential stress $\sigma_{\theta}$ for $t_{3}=100 \mathrm{~mm}$

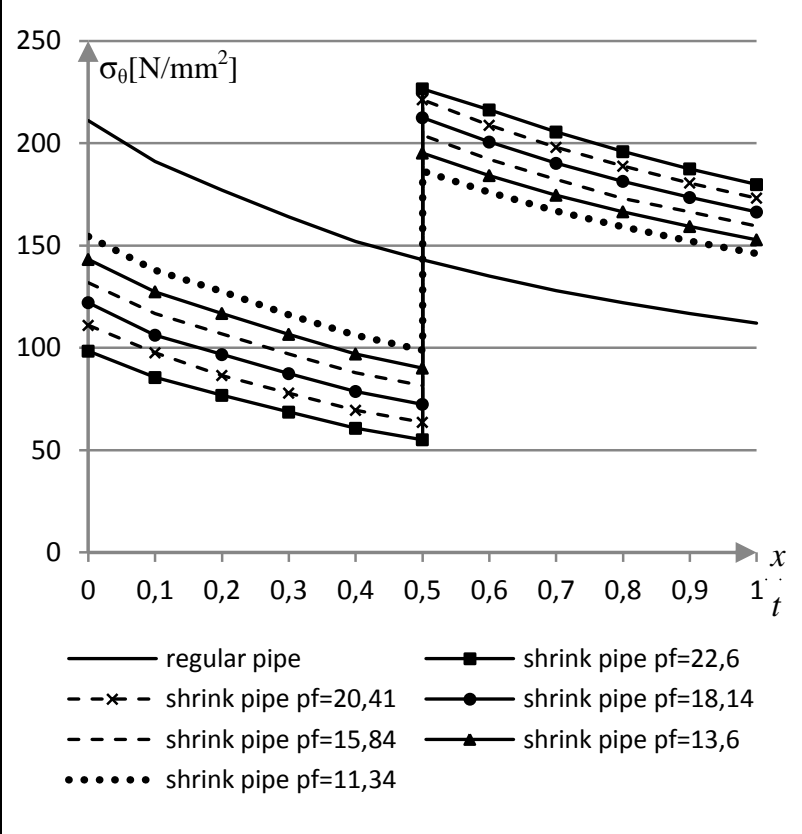

Fig. 4 Variation of the $\sigma_{\theta}$ stress on the pipe wall thickness

\subsection{Determination of the number of cycles required for the crack to penetrate the pipe wall}

In this study, the crack is generated on the inside surface of the pipe and its has elliptical shape (fig. 2) with semi-axis length of $a=0,508 \mathrm{~mm} ; c=2,59 \mathrm{~mm}$. Also, was taken into account the real variation of $\sigma_{\theta}$ stress along with direction of the wall thickness, as is presented in Tab. 1, 2 and 3. 
Given that it was used the principle according with the pipe durability is defined by the required number of cycles for the crack to penetrate the pipe wall, the obtained results are presented in Tab. 4 for the shrink pipe and in Tab. 5 for the regular pipe.

\begin{tabular}{|c|c|c|}
\hline \multirow{3}{*}{ Wall thickness } & $\begin{array}{c}\text { Shrinkage pressure } \\
p_{f}\left[\mathrm{~N} / \mathrm{mm}^{2}\right]\end{array}$ & $\begin{array}{c}\text { Durability } \\
N[\text { cycles }]\end{array}$ \\
\hline \multirow{5}{*}{$t_{1}=60 \mathrm{~mm}$} & 11,34 & 885.349 \\
\cline { 2 - 3 } & 13,60 & 997.689 \\
\cline { 2 - 3 } & 15,87 & 1.230 .233 \\
\cline { 2 - 3 } & 18,40 & 1.474 .604 \\
\cline { 2 - 3 } & 20,41 & 1.822 .810 \\
\hline \multirow{5}{*}{$t_{2}=80 \mathrm{~mm}$} & 22,60 & 2.205 .939 \\
\cline { 2 - 3 } & 11,34 & 2.603 .300 \\
\cline { 2 - 3 } & 13,60 & 3.165 .848 \\
\cline { 2 - 3 } & 15,87 & 3.923 .473 \\
\cline { 2 - 3 } & 18,40 & 4.986 .229 \\
\hline \multirow{5}{*}{$t_{3}=100 \mathrm{~mm}$} & 20,41 & 6.219 .801 \\
\cline { 2 - 3 } & 22,60 & 8.770 .416 \\
\cline { 2 - 3 } & 11,34 & 5.230 .686 \\
\cline { 2 - 3 } & 13,60 & 6.251 .196 \\
\cline { 2 - 3 } & 15,87 & 7.606 .436 \\
\cline { 2 - 3 } & 18,40 & 9.131 .762 \\
\cline { 2 - 3 } & 20,41 & 12.097 .666 \\
\hline \multirow{5}{*}{} & 22,60 & unlimited \\
\hline
\end{tabular}

Tab. 4. Durability for the shrink pipe loaded with inner pressure $p_{i}=100 \mathrm{~N} / \mathrm{mm}^{2}$

\begin{tabular}{|c|c|c|}
\hline Wall thickness & $\begin{array}{c}\text { Inner pressure } \\
p_{i}\left[\mathrm{~N} / \mathrm{mm}^{2}\right]\end{array}$ & $\begin{array}{c}\text { Durability } \\
N[\text { cycles }]\end{array}$ \\
\hline$t_{1}=60 \mathrm{~mm}$ & 100 & 458.848 \\
\hline$t_{2}=80 \mathrm{~mm}$ & 100 & 1.190 .950 \\
\hline$t_{3}=100 \mathrm{~mm}$ & 100 & 2.541 .287 \\
\hline
\end{tabular}

Tab. 5. Durability for the regular pipe loaded with inner pressure $p_{i}=100 \mathrm{~N} / \mathrm{mm}^{2}$

Fig. 5 represents the durability variation with respect to the shrinkage pressure cumulated with inside pressure and fig. 6 represent the durability variation of the regular pipe function to the wall pipe thickness.

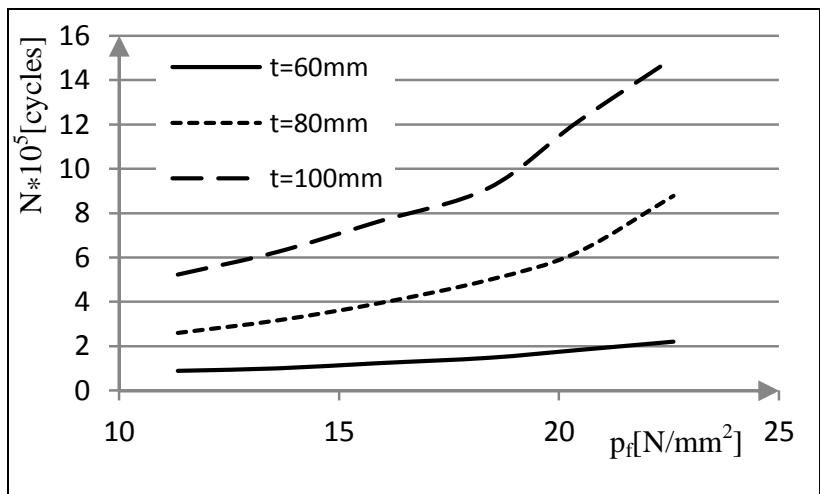

Fig. 5. Durability variation with respect to the shrinkage pressure

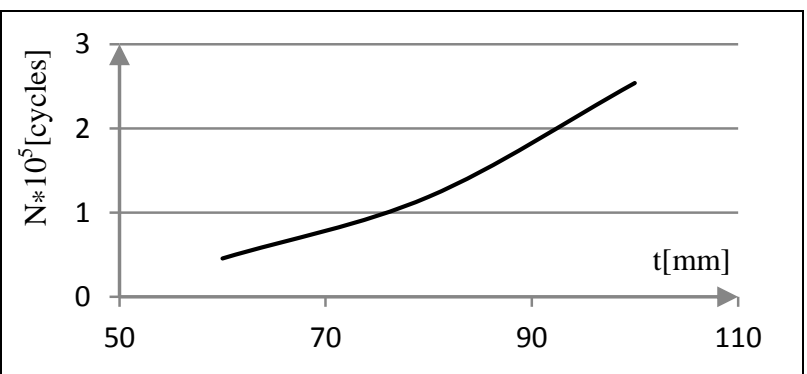

Fig. 6. Durability variation of the regular pipe function to the wall pipe thickness
4.3Analysing the influence of shrinkage pressure and the influence of the thickness of the pipe wall

From the above presented data its results that a significant durability growth is observed in case of the pipes made by shrinkage process, as it can be seen also form Tab. 5 .

\begin{tabular}{|c|c|}
\hline Wall thickness $t[\mathrm{~mm}]$ & Durability growth rate \\
\hline 60 & $1,92-4,8$ times \\
\hline 80 & $2,1-7,3$ times \\
\hline 100 & $2-4,7$ times \\
\hline
\end{tabular}

Tab. 5. Durability growth

Analysing fig. 5 it can be observed that the durability is increasing function to the pipe wall thickness $(t)$ and also with function to the pipe shrinkage pressure. Moreover, it can be seen that if the shrinkage pressure is increasing, the pipe durability is trending to unlimited values (in case of $t=100 \mathrm{~mm}$ ).

\section{CONCLUSION}

The main objective of the presented paper it was to determine the durability of thick-walled pipes obtained by shrinkage and to compare it with the durability of regular pipes. The main conclusion which can be emphasize is that the durability in case of shrink pipe is increasing greatly, proportionally with the shrinkage pressure.

The presented study contribute to the development of new future directions of research that is tying to answer to the following question: how the crack will propagate after it penetrate the inner pipe and it reaches the separation surface between those two shrink pipes? In one point from this surface the $\sigma_{\theta}$ stress is low for inner pipe and is high for the outer pipe as it can be seen in fig. 4 .

Another direction of study, important for future research, is the way in which the fatigue crack propagates when the shrinked tubes are made of different material.

\section{REFERENCES}

[1] NASGRO 5.01 Software(2007). Southwest Research Institute, Licente No. A50-0028

[2] Singh, P. K. (2003). Crack initiation and growth behaviour of circumferential cracked pipes under cyclic and monotonic loading, pp 629 - 640. International Jornal of Pressure Vessel and Piping. Vol 80, Issues 9

[3] Pintilie, G. \& Albut, A. (2009), The temperature influence on the durability of the transportation pipes, pp $1631-1634$. The 20th International DAAAM Symposium, 25 - 28th November Viena, Austria

[4] Pintilie, G. \& Albut, A. (2009), The wind effect on the aerial transportation pipes, pp 1735 - 1736. The 20th International DAAAM Symposium, 25 - 28th November, Viena, Austria

[5] Loghman, A., \& Wahab, M. A., (1996), Creep Damage Simulation of Thick-Walled Tubes using the \&Theta; Projection Concept, International Journal of Pressure Vessels and Piping, 67, pp. 105-111

[6] Sun, W., Hyde, T. H., \& Becker, A. A., (2002), Steady-State Creep Reference Rupture Stresses for Internally Pressurised Pipes for use in Life Prediction, International Journal of Pressure Vessels and Piping, 79(2), pp. 135-143

[7] Tutuncu, N. \& M. Ozturk, (2001). Exact solutions for stresses in functionally graded pressure vessels. Compos. Part B., 32, pp. 683-686 